\title{
RELAÇÕES ÉTNICO-RACIAIS E ENSINO DE HISTÓRIA NO BRASIL: O NEGRO NO SABER HISTORIOGRAFICO E SABER HISTÓRICO ESCOLAR
}

\author{
Elton Luis da Silva Júnior ${ }^{1}$ \\ Silviane de Carvalho Farias ${ }^{2}$
}

\begin{abstract}
RESUMO
Este estudo objetiva investigar as Relações Étnico-Raciais no contexto do saber historiográfico e saber histórico escolar no ensino de História. Para tanto, buscamos identificar as Relações Étnico-Raciais que historicamente foram demarcadas por contextos de invisibilidade, sobretudo quando relacionadas a historiografia africana e afro-brasileira. As discussões sobre as imagens dos negros nos saberes produzidos na historiografia brasileira nos remetem à análise das principais interpretações e debates historiográficos desenvolvidos sobre as observações equivocadas sobre o negro no Brasil. A pesquisa apresenta uma abordagem qualitativa com aplicação de pesquisa bibliográfica. Os resultados revelam que é necessário estabelecer um ensino de História que evidencie uma educação para as Relações Étnico-Raciais, mostrando a História do Brasil como uma sociedade multirracial e pluriétnica por meio da reversão de valores e conceitos centrados em uma perspectiva eurocêntrica que coloca o negro a margem da construção histórica e cultural do Brasil. Concluímos que desde que o ensino de História passou a ser uma disciplina escolar no Brasil o foco estrutural dela foi se modelando de acordo com determinado momento histórico, fazendo com que por muitos anos houvesse a invisibilização do negro na formação cultural do país.
\end{abstract}

Palavras-Chave: Ensino de História. Relações Étnico-Raciais. Saber Historiográfico. Saber Histórico Escolar.

\begin{abstract}
This study aims to investigate Ethnic-Racial Relations in the context of historiographic knowledge and school history knowledge in the teaching of History. To this end, we seek to identify the Ethnic-Racial Relations that have historically been demarcated by contexts of invisibility, especially when related to African and Afro-Brazilian historiography. The discussions about the images of the Negro in the knowledge produced in Brazilian historiography leads us to the analysis of the main interpretations and historiographic debates developed about the mistaken observations about the Negro in Brazil. The research presents a qualitative approach with the application of bibliographic research. The results reveal that it is necessary to establish a teaching of History that shows an education for Ethnic-Racial Relations showing the History of Brazil as a multiracial and multi-ethnic society through the reversion of values and concepts centered in a Eurocentric perspective that puts black people at margin of the historical and cultural construction of Brazil. We conclude that since history teaching became a school subject in Brazil, its structural focus has been modeled according to a certain historical moment, making blacks invisible in the country's cultural formation for many years.
\end{abstract}

Key Words: History Teaching. Ethnic-Racial Relations. Historiographic Knowledge. Historical School Knowledge.

Data de submissão: 22. 09. 2020

Data de aprovação: 26.10 .2020

\footnotetext{
${ }^{1}$ Mestre em Linguagens e Saberes na Amazônia, Linha de Pesquisa Educação, Cultura e Sociedade da Universidade Federal do Pará (UFPA), Campus Universitário de Bragança/PA. Graduado em Licenciatura em História (UFPA). E-mail: eltonluis@ufpa.br.

${ }^{2}$ Mestranda do programa de pós-Graduação em Linguagens e Saberes na Amazônia, Universidade Federal do Pará, Campus Bragança/PA. Graduada em Licenciatura em História. E-mail: silvianefarias@gmail.com
} 


\section{INTRODUÇÃO}

Para tanto, buscamos identificar as RER que historicamente foram demarcadas por contextos de invisibilidade, sobretudo quando relacionadas à historiografia africana e afrobrasileira. Para Gomes (2001); Munanga (2004) e Coelho (2009) as Relações Étnico-Raciais são um campo de conhecimento, de reconhecimento e valorização da cultura afro-brasileira e Africana, na perspectiva das múltiplas dimensões que envolvem a história, a cultura e a vida do negro no Brasil. Elas são compreendidas como uma categoria das relações sociais e partem de identidades culturais entre grupos que empregam e estruturam suas ações a partir do convívio social.

Consideramos dizer que o saber historiográfico está relacionado ao conhecimento acadêmico, ao saber que o egresso em formação deve apreender, e que é a principal referência do saber histórico escolar. Contudo, o saber escolar não se configura como um saber científico simplificado, tampouco é a simples difusão em linguagem apropriada a faixa etária de alunos do conhecimento produzido em Universidades ou Instituições de pesquisa. O Saber Histórico Escolar é o saber construído no dia a dia escolar, considerando o processo sócio cognitivo do aluno (MONTEIRO, 2003).

Monteiro (2003) compreende o saber escolar como um fator estruturante na perspectiva educativa. Esse caráter educativo estabelece que os saberes de referência estejam a serviço de uma proposta pedagógica que opere e atribua sentido ao saber interdisciplinar. Para a autora, a função pedagógica na prática educativa se insere em dois elementos estruturantes que são a axiologização (os valores que permeiam a formação oferecida) e a didatização, ou seja, as transformações a que o saber historiográfico é submetido com vistas aos propósitos educativos.

As discussões sobre as imagens do negro nos saberes produzidos na historiografia e no ensino de História nos remete à análise das principais interpretações e debates historiográficos desenvolvidos sobre as representações equivocadas sobre o negro no Brasil. Essas abordagens têm pautado diversas pesquisas de autores como Skdimore (1976), Munanga (2004), Pinsky (1994), Schwarcz (1993); Ortiz (2006), Coelho (2009), Santos (2009) que discutem as Relações Étnico-Raciais no contexto educacional brasileiro. Nesse sentido, o presente trabalho irá abordar as RER forjadas pelo discurso histórico do ensino de história a partir do diálogo com o saber historiográfico e saber histórico escolar.

Este estudo apresenta uma abordagem qualitativa por meio de pesquisa bibliográfica, a partir da análise interpretativa. De acordo com Severino (2010) esse tipo de método de pesquisa busca interpretar e dialogar com autores a partir de determinada temática, buscando explorar as ideias proposta nas obras selecionadas para o estudo.

A primeira etapa de interpretação consiste em situar o objetivo central do estudo a partir das discussões teóricas dos autores selecionados. Em seguida, buscamos identificar os pontos comuns e/ou divergentes entre os teóricos elegidos. A análise das obras selecionadas para a pesquisa nos possibilitou estabelecer uma interpretação crítica acerca do tema estudado.

Ao analisar os dados o estudo foi organizado a partir de uma discussão sobre os discursos raciais do final do século XIX, momento em que a representação do negro foi difundida negativamente pelas teorias raciológicas, biologizantes, tal como a ideia de inferiorizarão racial, que contaminaram os saberes produzidos no ensino de História, cujo imaginário racial foi construído em cima de páginas brancas a partir de construções epistemológicas que inferiorizam o negro no processo de construção social, racial e cultual no Brasil.

Em seguida, abordamos o processo de mudança de perspectiva historiográfica que primou por uma História social em detrimento de uma História tradicional permitindo que 
grupos, como africanos e afro-brasileiros, outrora marginalizados pelo saber historiográfico e saber histórico escolar pudessem emergir como agentes construtores da formação cultural do Brasil.

$\mathrm{Na}$ fase da leitura desenvolvemos a sistematização das ideias iniciais de construção da pesquisa, colocadas pelo referencial teórico constituindo interpretações das informações coletadas no estudo. Realizou-se a leitura geral das obras selecionadas, a fim de sistematizar as operações necessárias para a análise. Nesta fase o ponto de partida foi construir análises sobre como se configura as Relações Étnico-Raciais no ensino de História em sua articulação com saber historiográfico e saber histórico escolar.

Nesse sentido, o estudo bibliográfico se realizou por meio de matrizes teóricas diversas, ganhando formas particulares nas mãos de diferentes autores, tais como: Skidmore (1976), Munanga (2004), Bento (2014), Guimarães (2015), Bitencourt (2011), Monteiro (2003), Caimi (2015), entre outros que se dedicaram aos estudos, em suas distintas abordagens sobre Relações Étnico-Raciais, Ensino de História, saber historiográfico e saber histórico escolar.

Atualmente, a estrutura curricular, dos diferentes níveis de ensino, encontra-se mais flexível quando se fala nas possibilidades historiográficas de discussão sobre o tema em tela, aberto a um diálogo interdisciplinar e pluriétnico, permitindo que outras vozes pudessem emergir sob a ótica da História social. Um longo caminho ainda precisa ser trilhado, mas os avanços possibilitados pelas legislações (Lei 10.639/2003 e as Diretrizes Curriculares Nacionais para a Educação das Relações Étnico-Raciais) e pelos documentos oficiais que norteiam a educação no Brasil orientam para uma nova perspectiva curricular no ensino de História no que se refere inserção da temática Étnico-Racial, o que pode favorecer a edificação de novos conhecimentos sobre a temática no saber historiográfico e no saber histórico escolar.

\section{RELAÇÕES ÉTNICO-RACIAIS E ENSINO DE HISTÓRIA: INTERFACES COM O SABER HISTORIOGRÁFICO E SABER HISTÓRICO ESCOLAR}

No ensino de História o domínio da historiografia nos faz refletir sobre alguns aspectos que permeiam o ensino de História: o saber histórico escolar e o saber historiográfico. Para Coelho e Coelho (2019) o saber histórico está remetido aos subsídios que oferece à formação escolar, tal como, o incentivo ao amadurecimento cognitivo, ao desenvolvimento do pensamento formal em História, a partir do contato com o saber disciplinar. Nesse sentido, as abordagens sobre o passado conformam um conhecimento que visa, entre outros propósitos, a assimilação de competências e habilidades que tornem o estudante capaz de exercer a análise e a crítica da memória histórica.

Por sua vez, o saber historiográfico remete-se a uma das principais balizas da atuação do professor de História por constituir-se de um saber adquirido na formação docente. Concordamos com a análise de Coelho e Coelho (2019) que compreendem o Saber Historiográfico como um conjunto de atividades ocupadas com o conhecimento histórico. São as atividades que buscam dar conta da origem e do percurso da Disciplina, além de seus fundamentos teóricos e metodológicos. Comportam, portanto, atividades voltadas para a familiarização com períodos ou temas, aquelas que estabelecem diálogos com outras disciplinas e as responsáveis pelo tratamento de aspectos conformadores do ofício do historiador.

Nesse sentido, o conhecimento consistente sobre a disciplina implica em conhecer não apenas a estrutura do conhecimento histórico (saber historiográfico), mas também na apropriação de conhecimentos pedagógicos (saber histórico escolar) que lhe permitam a mobilização de estratégias e recursos que transformem o saber historiográfico em saber para 
ensinar, ou seja, em saberes válidos socialmente pertinentes ás características e finalidades da escola por meio de processos de transposição didática (CAIMI, 2015).

O saber historiográfico e o saber histórico escolar são duas categorias que nos ajudam a compreender e identificar os contextos em que as Relações Étnico-Raciais, sobretudo a historiografia do negro no Brasil, estiveram negligenciadas ou apresentadas de maneira estereotipada no ensino de História.

Neste estudo concordamos com a análise de Gomes (2001); Munanga (2004) e Coelho (2009) em que compreendem o conceito de raça a partir de uma construção política. O termo, nessa perspectiva, passa a conter um componente de combate ao racismo e a luta contra as formas de segregação baseadas na cor.

Igualmente, Gomes (2001) compreende raça como um termo que engloba os diversos grupos étnicos e raciais que formam o nosso país. Para ela, muitos pesquisadores têm rejeitado o termo raça em detrimento do termo étnico, como sendo o mais adequado para se entender às relações entre brancos e negros no Brasil pelo fato de o conceito de raça está ligada a ideia de um processo de dominação político-cultural.

Nos estudos sobre Relações Étnico-Raciais, outro conceito utilizado é o de etnia. Munanga (2004) e Gomes (2001) destacam o termo como um grupo que possuem um nível de coerência, origem e interesses em comum. Destacam ainda que etnia ajuda a definir os traços dos diferentes grupos humanos marcados por características históricas e culturais.

Um vocábulo que passou a ser utilizado no Brasil foi à expressão étnico-racial. O sentido está ligado às tensas relações raciais estabelecidas no Brasil, que estão além das diferenças de cor da pele ou de traços fenotípicos, que correspondem também a raiz cultural brasileira baseada na ancestralidade africana e indígena que se difere da visão de mundo, valores e princípios da origem europeia (BRASIL, 2004). É, portanto, uma dimensão política e cultural.

Nesta pesquisa, assumimos a dimensão das Relações Étnico-Raciais, como campo de conhecimento relacionados à dimensão política e cultural do termo, e, reportamo-nos que essa questão é de extrema relevância para ser discutida no processo de Formação de Professores, compreendendo que a formação para as Relações Étnico-Raciais não se encerra apenas com a inclusão de conteúdos específicos, mas se concretiza na experiência acadêmica, no âmbito universitário e para além das salas de aula.

\subsection{TEORIAS RACIAIS E O ENSINO DE HISTÓRIA}

Os saberes produzidos na historiografia brasileira acabaram sendo contaminados pelas teorias raciais do final do século XIX, em que um imaginário racial foi construído em cima de páginas brancas onde representação do negro foi difundida negativamente. Para Schwarcz (1993) no século XIX o termo raça surge como um mecanismo que classificava grupos humanos caracterizados como heranças físicas. Coelho $(2009$, p.35) estabelece que a emergência do termo esteja "[...] associada a toda uma série de calamidades impostas a certos grupos humanos por outros, tendo por base a crença infame que os homens se distinguem em raças", ou seja, no século XIX a conceituação de raça estava alicerçada na classificação hierárquica de grupos humanos em que a imagem do "homem branco" estava no topo do desenvolvimento cultural e social.

A História enquanto disciplina escolar no Brasil, com objetivos específicos definidos e caracterizados com um conjunto de saberes originados da produção científica com métodos pedagógicos próprios, ocorreu após a independência do Brasil quando se constituía o Estado Nacional e no processo de estruturação de um sistema de ensino para o império que colocava a questão da identidade no centro de suas reflexões sobre a construção da nação brasileira (FONSECA, 2011). 
A principal característica historiográfica nesse período era baseada na História política. No final do século XIX o historiador mais evidente no ocidente era Leopold Von Ranke, suas obras centravam-se no Estado, ou seja, a antiga história política recuperou a predominância (BURKE, 2012).

Nesse período histórico os governos europeus passaram a considerar a história como um meio de promover a unidade nacional, de educar para a cidadania, ou um meio de fazer propagandas nacionalistas, a História ganhava um teor mais "cientifico" a partir das análises de documentos oficiais (BURKE, 2012). Esse modelo historiográfico se perpetuou por muito tempo refletindo na maneira com que se ensinava a história, centrada apenas em grandes feitos e em grandes personalidades políticas da história.

A História tradicional privilegiava como fontes os documentos escritos, oficiais e não oficiais, sítios arqueológicos, edificações etc. Os sujeitos desse modelo historiográfico eram personalidades jurídicas, religiosas e militares, atores que apareciam como sujeitos individuais e únicos construtores da História (GUIMARÃES, 2015).

No Brasil, o ensino de História passa a ser um mecanismo do estado para formas "cidadãos" obedientes as leis e ao estado. A conformação de um indivíduo à vida civil passaria pela construção de um sistema educacional controlado pelo governo, e unificando seus pressupostos didático-pedagógicos em seus programas e currículos (FONSECA, 2011).

Analisando o ensino de História e os saberes produzidos, percebe-se um movimento duplo, que convergiam para negligenciar o negro no saber historiográfico e no saber Histórico escolar: primeiro, as teorias raciais postulavam a inferiorização do negro enquanto um agente possuidor da própria qualidade de ser humano; e segundo o ensino de História não privilegiava a História social, mas sim uma história que tinha por base os registros oficiais e a centralização de "grandes personagens da História".

Até abolição da escravatura o negro não existia como cidadão, sua ausência no plano literário refletia diretamente nas ciências sociais. Segundo Ortiz (2006) é no final do século XIX que se engendra o mito das "três raças" onde a raça branca era tida como superior ligada ao gosto pelo trabalho, a força e persistência.

Com o fim do sistema escravocrata houve um intenso fortalecimento das cidades letradas, aliada a um discurso de um projeto nacionalista em que teorias raciais ganharam um novo sentido: o de classificar as raças em bases hierárquicas de inferioridade. Após a abolição os pensadores brasileiros centravam-se em uma questão crucial: a de estabelecer uma nação e uma identidade nacional. Mas, para se constituir estes elementos a elite brasileira teria que lidar com uma nova categoria de cidadãos: os ex- escravos negros (MUNANGA, 2004).

Para resolver o "problema" do negro no Brasil, a solução brasileira foi a tentativa de postular a ideia de "branqueamento" da população brasileira. Segundo Skidmore (1976) a teoria brasileira do branqueamento era uma teoria peculiar do Brasil, poucas vezes apresentadas como formula científica e jamais praticada em países europeus ou no continente norte-americano.

A tese do branqueamento baseava-se na suposição de superioridade da raça branca. Essa presunção inicial juntava-se a mais duas: a primeira era a de que a população negra diminuía progressivamente pela sua própria condição "natural" de desorganização, suposta taxa de natalidade mais baixa e maior incidência de doenças. A segunda, a miscigenação produzia "naturalmente" uma população brasileira mais clara, em parte porque o gene branco era mais resistente e em parte as pessoas estavam procurando parceira com a pele mais clara (SKIDMORE, 1976).

Nessa postulação racial o branco aparece como o modelo universal, alvo do desejo dos não brancos. Considerando seu grupo como padrão de referência de toda a espécie humana a elite brasileira fez uma apropriação simbólica crucial que fortaleceu a autoestima e o 
autoconceito do grupo branco em detrimento dos demais, essa apropriação acabou por legitimar sua supremacia no meio social, racial, político e cultural no Brasil (BENTO, 2014).

Paralelo a política do branqueamento, no ensino de História pouco eram os espaços destinados a outras maneiras de se construir conhecimentos históricos, o saber historiográfico produzido centrava-se em questões que enalteciam personagens individuais, o que refletia diretamente no saber histórico escolar produzido no cotidiano das escolas brasileiras. Nesse modelo, a historiografia do negro limitou-se ora ao vitimismo escravocrata que os ligava ao trabalho pesado, ao castigo físico e a violência, ora mostrando o negro em uma harmonia racial com o branco.

\subsection{O NEGRO NA ABORDAGEM HISTORIOGRÁFICA BRASILEIRA}

Até meados do século XX a produção historiográfica brasileira continuava caracterizada por traços tradicionais, comumente chamado de positivista ${ }^{3}$. Segundo Fonseca (2011), os livros didáticos de História acompanharam essa tendência, onde a História apresentada centrava suas discussões especialmente em questões militares e políticas. As temáticas construíam uma abordagem profundamente nacionalista, dando a alguns acontecimentos históricos no Brasil um caráter de consolidação da identidade que excluía dessa identidade nacional a população afro-brasileira.

Esse modelo historiográfico influenciou diretamente o ensino de História no Brasil ${ }^{4}$ no que se refere a invisibilidade da população negra e sua contribuição cultural na historiografia brasileira, percebe-se que durante muito tempo identificar a História da África e dos afrobrasileiros a partir da perspectiva social e cultural era praticamente improvável nas produções historiográficas. Pinsky (1994) faz críticas ao reducionismo historiográfico, que colocou os povos africanos ligados uma visão simplista (economicista) e coisificada sobre a introdução de escravos negros no Brasil e aos interesses mercantis do tráfico negreiro.

Em 1930, operava-se no Brasil concepções, que buscavam novos caminhos para as indicações políticas do país, tendo como principal orientação o desenvolvimento social do Brasil. Porém, essa orientação não podia ser nos moldes das teorias raciais do final do século XIX, tomadas como obsoletas. Foi então que Gilberto Freyre (1934) fez seu aparecimento na historiografia para atender a essa demanda (ORTIZ, 2006).

Segundo Munanga (2004) Freyre retoma a temática racial deslocando o eixo da discussão, operando a passagem do conceito de "raça" ao conceito de cultura. Para Ortiz (2006) essa passagem de conceitos permitiu um maior distanciamento entre o biológico e o cultural, bem como eliminar diversas dificuldades colocadas a respeito da herança atávica do mestiço.

Freyre (1971) identifica a sistematização da ideia de uma democracia racial no Brasil, ao mesmo tempo em que teria se distanciado do racismo, prevalecente nas Ciências Sociais no início do século XX, teria criado também uma imagem idílica do Brasil colonial. Segundo o

\footnotetext{
${ }^{3} \mathrm{Na}$ França, os anos de 1920, testemunharam um movimento rumo a um novo tipo de história, conduzido por dois professores da Universidade de Estrasburgo, Marc Bloch e Lucien Febre. A revista fundada por eles, annales d'Histoire économique et sociale (Anais de História Econômica e Social), fez críticas implacáveis a historiadores tradicionais (Positivistas). Febvre e Bloch, apunharam-se ao predomínio da história política (BURKE, 2012). Segundo Burke (2012), Febvre e Bloch ambicionavam estabelecer uma história mais ampla e mais humana, que abrangeria todas as atividades humanas e estaria menos preocupada com a narrativa de eventos do que com a análise das estruturas, termo que se tornou o preferido de historiadores franceses da chamada "Escola dos Annales" (BURKE, 2012). A História Social proposta por Febvre, Bloch e Braudel influenciaram as novas gerações de historiadores, percebendo os processos históricos a partir do cotidiano, da cultura e do social.
} 
autor, os escravos que viviam nos engenhos eram, de modo geral, bem tratados, e sua sorte menos miserável do que as dos trabalhadores europeus.

Na concepção do autor a cordialidade entre a casa grande e a senzala era harmônica, do contrário, para Hasenbalg (1979) o mito da democracia racial freyreana serviu como uma reconstrução fantasiosa do passado da população brasileira, uma falsa ideologia e falsa ilusão definida pela "[...] ausência de preconceito e discriminação racial no Brasil e, consequentemente, pela existência de oportunidades econômicas e sociais iguais para negros e brancos" (HASENBALG, 1979, p. 242).

Segundo Munanga (2004) a grande contribuição de Freyre foi ter mostrado que negros, índios e mestiços tiveram contribuições positivas na cultura brasileira: influenciaram profundamente no modo de vida da classe senhorial em matéria de comida, indumentária e sexo. A mestiçagem, que no pensamento de Nina Rodrigues, causava danos irreparáveis ao Brasil, era vista por Freyre como uma vantagem imensa que permitiu completar definitivamente os contornos de uma identidade que há muito vinha sendo desenhada no Brasil.

O mito da democracia racial baseada na dupla mestiçagem, biológica e cultural, exerceram uma forte influência na sociedade brasileira. Exaltava-se a ideia de convivência harmoniosa entre os indivíduos de todos os grupos étnicos, permitindo às elites dominantes dissimular desigualdades e impedindo que aqueles tidos como não brancos percebessem os sutis mecanismos de exclusão racial no Brasil (MUNANGA, 2004).

Skdimore (1976) destaca que Freyre não privilegiou em sua análise as assimetrias históricas de poder entre os senhores e escravos, em sua perspectiva reforçou a ideia de branqueamento, mostrando que a elite (branca) adquirira traços culturais positivos em detrimento dos negros brasileiros.

Essa linha interpretativa da escravidão no Brasil representada por Freyre exerceu uma forte influência no saber histórico escolar, em especial, nas décadas de 1950 e 1990. Monteiro (2003), constatou que ao fazer referência a "escravidão" os professores optaram por construir conceitos a partir da imagem do africano relacionando-o ao processo escravocrata, como sendo uma condição natural do negro africano, não problematizando que a escravidão se deu em um processo histórico e não étnico.

A autora destaca que o africano e o indígena são colocados em um demasiado processo simplista que sempre os ligam a historiografia europeia, ora na experiência portuguesa com os escravos africanos, ora na possibilidade de utilizar o indígena na disponibilidade do manejo das terras no período colonial brasileiro, o que acaba gerando uma visão negativa sobre aqueles grupos.

O negro na História ensinada prevalece sendo representado por meio de uma lógica unilateral, que o coloca em uma condição ligada a escravidão e dificilmente são mostrados em situações que possibilitem uma nova maneira de construir epistemologias positivas sobre a população negra. $\mathrm{O}$ negro escravo do passado tornou-se sob a ótica do preconceito racial o negro marginal do presente (OLIVEIRA, 2000).

Muitos professores formados ou em formação, com algumas exceções, não tiveram em suas graduações, contato com disciplinas específicas sobre saberes historiográficos relacionados as relações étnico-raciais, sobretudo referente a História Africana ou a cultura afro-brasileira. Soma-se a esse relevante fator a constatação de que em muitos livros didáticos de História não reservam para a África e cultura afro-brasileira espaços adequados, pouco atentando para a produção historiográfica sobre o continente africano (GUIMARÃES, 2015).

A disciplina História lecionado nas escolas brasileiras, entre as décadas de 50 e 60 do século passado, contemplava apenas "[...] a formação cívica, no intuito de ajustar os jovens para os interesses do Estado, pautada no ideal de progresso, tendo como base teórica a historiografia tradicional positivista e eurocêntrica" (MOREIRA, 2015, p. 38). Desta forma, 
muitos grupos sociais não eram vistos como protagonistas da história e acabaram sendo negligenciados pelo modelo historiográfico tradicional, em especial questões relacionadas as contribuições culturais que africanos e indígenas desempenharam na formação cultural do Brasil.

Durante a década de 50 os saberes priorizados no ensino de História estava relacionada as práticas tradicionais que evidenciava a unidade e a continuidade da História, focadas no sentimento do civismo, tradição, família e nação, que pouco ou quase nada fazia referencias as relações étnico-raciais no saber histórico escolar (FONSECA, 2011).

O modelo unilateral eurocêntrico, que por muito tempo presidio a seleção dos conteúdos escolares e a sua consequente interferência no saber historiográfico e no saber histórico escolar, deveria ser substituído por uma perspectiva reflexiva em que no ensino a História do Brasil seja entendida em escala mais ampla, não limitada ao conhecimento baseado em uma linha cronológica eurocêntrica (BITTENCOURT, 2011).

Nas produções didáticas desse período os saberes produzidos colocavam a responsabilidade pela existência da escravidão aos próprios africanos, em um processo "natural" de inferiorização frente aos brancos. O negro africano era mostrado pela ótica da economia mercantilista, enfatizando-se a importância do tráfico de escravos e seus lucros como motivadores da chegada dos africanos no Brasil.

As produções didáticas, segundo Bittencourt (2011), têm de ser analisadas por meio de uma construção crítica, pois são importantes veículos portadores de um sistema de valores ideológicos e culturais. Os textos e ilustrações de obras didáticas transmitem estereótipos e valores dos grupos dominantes, generalizando temas, como família, criança, etnia, raça de acordo com os preceitos da sociedade branca burguesa nos saberes produzidos no ensino de História.

Não diferente da década anterior, os anos 60 mostraram um ensino de História que centralizava os saberes a herança tradicional historiográfica, onde as diretrizes norteadoras enfatizavam principalmente fatos políticos e as bibliografias dos "brasileiros celebres", entre os quais figuravam "personagens" do regime militar brasileiro (FONSECA, 2011).

Nos anos iniciais da ditadura militar o negro na História do Brasil era representado por uma visão unilateral da mão-de-obra, não apenas textualmente, mas também por meio de imagens ilustrativas nos materiais didáticos. O saber histórico escolar produzido centrava as discussões sobre o negro partindo de uma perspectiva da exploração econômica, alimentando uma visão maniqueísta da História, tirando dos afro-brasileiros e da História africana outras orientações ou ações promovidas por eles na construção cultural do Brasil (FONSECA, 2011).

Nos anos de 1970, o cenário político brasileiro foi protagonizado por novos atores sociais que entravam em cena por meio dos movimentos populares, principalmente ligados a questão de gênero e etnia, reivindicavam uma maior participação e reconhecimento de direitos e cidadania. Nesse período as questões étnico-raciais entraram na agenda de lutas, de modo especial, dos movimentos sociais de resistência da comunidade negra para que o Governo Federal instituísse políticas de ações afirmativas para a superação de desigualdades raciais no Brasil (GUIMARÃES, 2015).

Esses movimentos sociais, como o movimento indigenista reivindicavam do Governo Federal a demarcação de terras indígenas e o direito a própria cultura, já os movimentos consciência negra lutavam contra "[...] quaisquer formas de preconceito e discriminação racial, bem como pelo direito à diferença, pautada no estudo e valorização de aspectos da cultura afro-brasileira" (FERNANDES, 2005, p. 381). Para ele, é neste contexto que a valorização da diversidade étnico-cultural se insere no sistema educacional brasileiro, sinalizando a introdução de conteúdos sobre a história da África e do negro em nosso país. 
Essas lutas refletiram diretamente no ensino de História, na construção de uma nova perspectiva sobre as relações étnico-raciais. Elas passaram a frequentar discussões sobre demandas educacionais para a inclusão de conteúdos referentes a História, Cultura Africana e Afro-brasileira, juntamente com a desconstrução das imagens estereotipadas que historicamente foram mostradas no saber historiográfico e saber histórico escolar da educação brasileira (GUIMARÃES, 2015).

Entre o final da década de 1970 e início dos anos de 1980, o processo de redemocratização política do Brasil e suas implicações na produção acadêmica em História acabaram influenciando na elaboração de coleções didáticas para o ensino de História, construindo novas epistemologias sobre o papel do negro na formação cultural do Brasil.

$\mathrm{Na}$ década de 80 assistimos a "[...] uma nova forma de atuação política dos negros e negras brasileiros [...] passaram a atuar ativamente por meio dos movimentos sociais sobretudo os de caráter identitário, trazendo diversas problematizações nas formas de atuação política" (GOMES, 2010, p. 2-3). Para a autora, as reinvindicações do Movimento Negro indagam o Estado, a esquerda brasileira e os movimentos sociais sobre a sua neutralidade de posicionamento diante da centralidade da raça na formação do país.

Com o fim do regime militar, aliado a todas as influências da História Nova ${ }^{5}$, a disciplina História passou a ser percebida como uma importante ferramenta na construção de mudanças sociais. Para tanto, seria necessário modificar a estrutura curricular até então baseada em uma perspectiva unilateral que de modo sútil ou explícito excluíam grupos étnicos do protagonismo historiográfico para a formação cultural brasileira no saber historiográfico e histórico escolar (GUIMARÃES, 2015).

Nos anos 90 houve um significativo processo de renovação da historiografia brasileira, sobretudo, na influência cada vez mais nítida da chamada "História Nova". Para a autora, é nesse momento que os programas curriculares e os livros didáticos passam a incorporar novas tendências da historiografia contemporânea, como a História das Mentalidades e do Cotidiano, ainda hoje predominantes quando se fala em inovação das abordagens historiográficas. Esse novo modelo historiográfico possibilitou que atores sociais outrora negligenciados pudessem aparecer positivamente a partir de uma perspectiva social, étnica e cultural (FONSECA, 2011).

Nessa nova configuração novos temas e sentidos historiográficos surgem para a disciplina: questões sociais; direitos humanos; relações de gênero; corpo; alimentação; relações étnico-raciais (PINSKY, 1994). Isso demonstra que a disciplina passou a construir sentidos históricos por meio de temas que fazem parte do cotidiano escolar, não mais um ensino estático que pouco fazia sentido para os alunos em situação escolar.

Essa flexibilização possibilitou que as Relações Étnico-Raciais entrassem para a pauta de discussões educacionais no que se refere a inclusão da História Africana e Cultura afrobrasileira nos currículos da educação nacional. Essa nova configuração tornou-se ainda mais evidente após a promulgação da nova Lei de Diretrizes e Bases da Educação.

A partir da promulgação Lei de Diretrizes e Bases da Educação-LDB (Lei Federal n ${ }^{\circ}$ 9.394/96), diversos artigos vão fazer referência a valorização da miscigenação cultural, como

\footnotetext{
${ }^{5}$ A História nova, ocupa-se com tudo aquilo que homens e mulheres fizeram no passado e fazem no presente, ela considera que existem inúmeras formas de viver e representar o presente (BRAUDEL, 1992). Assim, temas outrora negligenciados pela historiografia passaram a ser objeto de investigação (BURKE, 2012). Esse modelo historiográfico abriu espaço para novas tendências da historiografia, principalmente a social. Novos sujeitos passam a emergir: Negros, índios, ricos, pobres, homens e mulheres, governantes, governados. A História passa a ser percebida não mais como individualizada, mas por movimentos sociais, pela classe trabalhadora, pelos militantes (GUIMARÃES, 2015). O historiador passa a dialogar, interrogar, analisar, confrontar e produzir conhecimentos que não são a mera descrição de registros ou documentos, mas sim uma elaboração historiográfica a partir de uma perspectiva cultural, do cotidiano, em um diálogo interdisciplinar (BRAUDEL, 1992).
} 
o Art. $26 \S 4^{\circ}$, ao definir que “[...] o ensino de história do Brasil levará em conta as diferentes culturas e etnias para a formação do povo brasileiro especialmente as matrizes indígenas, africanas e europeias" (BRASIL, 1996).

Portanto, apesar de ainda não estabelecer a obrigatoriedade do ensino de história e cultura africana e indígena, a LDB no 9.394/96 já sinalizava que deveria ser levando em consideração as três matrizes formadoras da sociedade brasileira. $\mathrm{O}$ debate social provocado por ocasião da promulgação da Lei de Diretrizes e Bases (Lei $n^{\circ}$ 9.394/96) reconfiguraram modificações educacionais como a flexibilização curricular, pautas relativas à inclusão e a reafirmação da autonomia docente.

A importância de serem discutidas as relações étnico-raciais no ensino de História está principalmente em dar visibilidade ao tema a partir de uma construção cultural, com um sentido histórico baseado na compreensão da diversidade. Questões referentes a temática necessitam de um olhar crítico dos professores de História, sobretudo, no processo de transpor didaticamente epistemologias que desconstruam elementos negativos da historiografia africana produzidos no saber histórico escolar.

Após um longo processo de lutas e reinvindicações promovidas pelo Movimento Negro, é sancionada a Lei Federal $n^{\circ} 10.639 / 2003$ que determinava a obrigatoriedade da inclusão no currículo das redes de ensino estudos sobre a História e Cultura africana e Afrobrasileira (GUIMARÃES, 2015).

A edição da Lei 10.639/03 ocorreu na esteira do complexo processo de reinvindicações do Movimento Negro, marcado por reflexões a respeito de desigualdades raciais. Possibilitou que novas epistemologias sobre as relações étnico-raciais se intensificassem em discussões propostas no saber historiográfico e no saber histórico escolar. Suas transformações no ensino produziram tensões entre a ampliação dos direitos de cidadania do país e principalmente a crescente compreensão da necessidade de enfrentamento do racismo e suas diversas ramificações na sociedade e no âmbito educacional.

A publicação da Lei $n^{\circ} 10.639 / 03$ ocorreu em um contexto social e educacional de busca por valorização das culturas afrodescendentes, em um cenário historiográfico marcado pela invisibilidade destas culturas, com forte atuação do movimento negro no Brasil. A legislação possibilitou, também, à sua maneira, o enfrentamento crítico a um ensino de História centrado em narrativas eurocêntricas, em que os registros sobre as relações étnicoraciais, sobretudo a História Afro-Brasileira, foram ignorados, invisibilizados, silenciados ou compareceram, via de regra, de forma estereotipada no saber historiográfico e histórico escolar (GUIMARÃES, 2015).

Essa legislação visa recuperar a diversidade na formação cultural do Brasil e fazer jus à riqueza da História híbrida em povos culturais. Nesse contexto, as RER passaram a ser discutido de modo "obrigatório" nos diversos níveis de ensino da educação nacional, o que gerou mudanças na maneira com que se discutia e se pensava a História da África e da Cultura Afro-Brasileira, principalmente na reconfiguração da temática no saber historiográfico e no saber histórico escolar.

Para auxiliar o disposto na Lei $n^{\circ} 10.639 / 2003$, bem como a necessidade de normas complementares para os sistemas de ensino que orientassem os profissionais da educação na maneira de ser trabalhada a questão étnico-racial no âmbito escolar, o Conselho Nacional de Educação - CNE aprovou a Resolução 1 de 17/04/2004, que institui as Diretrizes Curriculares Nacionais para o Ensino das Relações Étnico-Raciais e para o Ensino de História e Cultura Afro-Brasileira e Africana.

A partir da elaboração das DCNRER as escolas da Educação Básica passam a ter um documento oficial que busca aprofundar os dispositivos legais previstos na Lei $\mathrm{n}^{\circ}$ $10.639 / 2003$ no sentido de orientar práticas pedagógicas que construa positivamente a cultura afro-brasileira e africana (SANTOS, 2009). 
A autora analisa que tanto a implementação da Lei Federal $n^{\circ} 10.639 / 2003$ e das DCNRER vêm acrescentar às "[...] demandas que o Movimento Negro reivindicavam, bem como de intelectuais e de outros movimentos sociais na luta pela superação do racismo e da discriminação racial existente na sociedade brasileira" (idem, 2009, p. 151).

Estes instrumentos demarcadores possibilitaram também uma nova postura na inserção de componentes curriculares voltas para os cursos de formação docente em História capazes de construir saberes historiográficos adequados a promover a desconstrução da memória histórica estereotipada sobre a população negra concebida no saber histórico escolar.

Entendemos que a importância destas modificações não está necessariamente na obrigatoriedade de se inserir no ensino as temáticas sobre a História África e cultura afrobrasileira, mas sim nos desafios impostos pela lei ao saber historiográfico e histórico escolar no que pese a redefinição da memória histórica sobre a população negra na História do Brasil e enfrentar preconceitos e estereótipos e desconstruir mitos raciais.

A escola como instituição social tem um papel fundamental na necessidade de reconhecer e valorizar a História do povo negro brasileiro, sobretudo em uma nova postura que perpasse pela visibilidade do patrimônio cultural e histórico afro-brasileiro, além de mudanças no discursos que tornem possível a desconstrução do mito em que a sociedade brasileira vive em harmonia racial (SANTOS, 2009).

Empreender este tipo de investigação implica em construir epistemologias no saber histórico escolar que edifique positivamente, desde o saber historiográfico, as relações étnicoraciais em uma análise de compreensão no ensino de História sobre o protagonismo do negro na História do Brasil.

Para tanto, evidencia-se a necessidade de assegurar na formação inicial de professores de História epistemologias que promovam no saber historiográfico ações educativas que, por meio de seus componentes curriculares, sejam multiculturalmente e interdisciplinarmente orientadas. As relações étnico-raciais devem perpassar por todo o processo de formação inicial para que ao chegar ao ensino básico o professor de História tenha um aparato teórico e didático para desconstruir estereótipos e promover uma educação que valorize a diferença e seja etnicamente diversa no saber histórico escolar (GUIMARÃES, 2015).

Nesse sentido, a mudança estrutural nos currículos proposta por essas legislações abrem caminhos para a construção de uma educação antirracista e mais flexível do ponto de vista cultural, que acarreta em uma ruptura epistemológica, principalmente nos saberes produzidos nas instituições educacionais, na medida em que torna público e legítimo o "falar" sobre a questão afro-brasileira e africana nos currículos.

No texto da Base Nacional Comum Curricular - BNCC, referência nacional e obrigatória para a formulação dos currículos dos sistemas e das redes escolares dos estados, do DF e dos municípios e das propostas pedagógicas das escolas, verifica-se conteúdos sobre a temática das relações étnico-raciais no Brasil que devem ser seguidos pela Educação Básica no Brasil. A BNCC constrói diretrizes que auxiliam nas construções dos Projetos Políticos Pedagógicos (PPP) que deverão surgir de sua observância, bem como de outros materiais que norteiam a educação no Brasil.

O documento estabelece habilidades e competências específicas sobre as relações étnico-raciais a serem observadas no âmbito de políticas educacionais para diversas disciplinas que compõe o ensino básico do país, em nosso caso destacaremos as propostas no ensino de História.

$\mathrm{Na}$ área do ensino história é que se encontra a maior parte das indicações para a construção de conteúdos com foco em Educação para as Relações Étnico-Raciais, sobretudo na História e Cultura africana e afro-brasileira, respaldados nas propostas conceituais sobre a "acentuada diversidade" na formação dos povos; condições sociais; grupos migrantes; diversidade étnico-racial; cultural e cidadania. 
Nas habilidades e competências percebe-se que existe uma "preocupação" da BNCC em possibilitar a desconstrução de conceitos e ressignificação dos termos e valores que deram base à análises equivocadas sobre os negros no Brasil, difundidos principalmente no saber histórico escolar ao longo dos anos.

Apesar dos aparentes avanços, a Associação Nacional de Pós-Graduação e Pesquisa em Educação (ANPED) promoveu duras críticas a BNCC, principalmente, com relação à sua metodologia de construção, além do modo duvidoso da consulta utilizada como meio de legitimar a participação popular nesse processo, uma vez que especialistas, intelectuais, associações da sociedade civil e professores, que inicialmente ocuparam esse espaço, foram sendo substituídos, sendo que sua última versão contava com a presença maciça do MEC e representantes de empresas e grupos privados (ANPED, 2017).

Dessa forma, a versão final da BNCC culminou num texto que primou muito mais pela exclusão e omissão, tornando-se um documento que não reflete a diversidade do diálogo cultural estabelecido em muitas contribuições recebidas de profissionais que agem no cotidiano educacional brasileiro (ANPED, 2017). Rocha e Pereira (2016) descrevem a BNCC como práticas de controle e tentativa de homogeneidade e uniformidade do ensino, consoante as políticas neoliberais, vinculadas às políticas de avaliação, buscando formar indivíduos flexíveis a adaptar-se ao sistema mercadológico capitalista em detrimento de uma formação emancipatória do cidadão. Também a descrevem como instrumento de regulação, reprodução da experiência internacional.

A BNCC está longe de atender as demandas propostas pela Lei $\mathrm{n}^{\mathrm{a}} 10.639 / 03$ e as DCNRER, ao priorizar uma base comum que favorece o interesse mercadológico e não o social o documento se distância da busca de um ensino que de fato respeite as diferenças. Reforça-se nas entrelinhas da BNCC a segregação, a educação brasileira retrocede na luta por igualdade de direitos educacionais e na formação de um cidadão crítico e participativo.

Apesar dos avanços, mesmo após mais de 15 anos da promulgação da lei 10.639/2003, aspectos da cultura afro-brasileira ainda são mostrados em sala de aula como algo incidental, por meio de abordagens festivas que aparecem isoladamente do saber histórico escolar cotidianamente construindo (COELHO e COELHO, 2018).

Para eles, esse quadro está relacionado com a maneira pela qual a legislação é percebida, pois em muitos casos o entendimento é de que basta apenas inserir alguns conteúdos relacionados a história africana e afro-brasileira, "[...] o que se tem constatado ao longo dos últimos anos é um acrescentamento de conteúdos ao currículo da Educação Básica" (idem, 2018, p. 3).

Segundo os autores, desde o ano de 2003 houve um aumento dos espaços destinados a História da África e Cultura Afro-Brasileira nos livros didáticos e sua consequente produção no saber histórico escolar. Porém, isso não significa que houve uma alteração na perspectiva eurocêntrica acerca da História do Brasil presentes naquelas obras " [...] continua soberana a perspectiva eurocêntrica, segundo a qual a história confunde-se com a trajetória europeia, a qual intervêm e significa a trajetória brasileira" (COELHO e COELHO, 2018, p.4).

Isso requer profundas transformações nos currículos e projetos pedagógicos dos cursos de formação de professores, que questionem o lugar ocupado pela historiografia africana nos saberes historiográficos construídos nos cursos superiores de História (Idem, 2015). Coelho e Coelho (2018) asseguram a importância de formar docentes capazes de concretizar as diretrizes e promover uma educação que esteja ligada ao respeito, a diferença, a pluralidade étnica, a diversidade cultural e que permaneça voltada a valorização de todo e qualquer grupo humano, e que tenham "[...] condições de subverter as estereotipias cristalizadas e disseminadas ao longo da história da educação brasileira" (SANTOS, 2009, p. 154).

As legislações não alteram o fato de que tanto a História da África quando a Cultura Afro-brasileira permanece como elementos que são externos aos currículos da educação 
brasileira, sobretudo, ligados a conteúdos relacionados a episódios isolados do cotidiano escolar. Para Coelho e Coelho (2018) os escopos das legislações exigem mais do que o conhecimento do saber historiográfico; ela demanda, principalmente que o professor tenha um domínio de habilidades e competências capazes de construir uma crítica ao eurocentrismo possibilitando subsídios historiográficos que promova uma educação inclusiva.

Rever as práticas pedagógicas no currículo é não aceitar um discurso democrático falso, como uma educação igual para todos ou todos são iguais, pois isto não ameniza as diferenças sociais e étnico-raciais presentes na sociedade brasileira, pelo contrário, reforça ainda mais a desqualificação educacional e as desigualdades sociais e culturais existentes no país (GOMES, 2006).

O Ensino de História encontra-se inserido em um contexto que existe a necessidade de ser reconstruído um cenário epistemológico positivo sobre a educação para as relações étnicoraciais no Brasil, e que essa reconstrução seja refletida no saber historiográfico e saber histórico escolar. Para tanto, destaca-se que a História da África e da Cultura Afro-brasileira deve ser pensada na perspectiva da História social, respeitando as diferenças e construindo um cenário educacional mais igualitário.

\section{CONSIDERAÇÕES FINAIS}

É importante estabelecer um ensino de História que evidencie uma educação para as relações étnico-raciais mostrando a História do Brasil como uma sociedade multirracial e pluriétnica por meio da reversão de valores e conceitos centrados em uma perspectiva eurocêntrica que coloca o negro a margem da construção histórica e cultural do Brasil.

A Lei 10.639/03 e as DCNRER são marcos importantes no que se refere a superação de práticas racistas e desigualdades raciais na educação brasileira, estes mecanismos institucionais vislumbram modificações e reconfigurações dos currículos e práticas pedagógicas interculturais com o propósito de suprimir práticas racistas e discriminatórias no contexto escolar.

Os desafios, os avanços e as possibilidades para a execução, em ações e práticas pedagógicas propostas na lei 10.639/03, DCNRER são frutos de diversas reinvindicações do Movimento Negro, estas conquistas refletem anseios de respeito a diferença e a valorização cultural de um povo que contribui de maneira importante em diversos momentos históricos da sociedade brasileira.

Atualmente, a estrutura curricular do ensino de História encontra-se mais flexível, aberto a um diálogo interdisciplinar e pluriétnico, permitindo que outras vozes emerjam sob a perspectiva da História social. Um longo caminho ainda precisa ser trilhado, mas os avanços possibilitados pelas legislações e pelos documentos oficiais que norteiam a educação no Brasil orientam para uma nova perspectiva curricular na inserção da temática étnico-racial, o que pode favorecer a edificação de novos conhecimentos sobre as relações étnico-raciais no saber historiográfico e no saber histórico escolar.

\section{REFERÊNCIAS}

ANPED. Associação Nacional de Pós-Graduação e Pesquisa em Educação (ANPED) e a Base nacional Comum Curricular (BNCC). 2017. Disponível em: http://www.anped.org.br/news/documento-expoe-acoes-eposiciomanetos-da-anped-sobrebncc. Acesso em: 15 jul. 2020.

BENTO, Maria Aparecida Silva (Org.). Psicologia social do racismo: estudos sobre branquitude e branqueamento no Brasil. $6^{\circ}$ ed. Petrópolis, RJ: Vozes, 2014. 
BITTENCOURTT, Circe Maria Fernandes. Ensino de História Fundamentos e Métodos. $4^{\text {a }}$ ed. São Paulo: Cortez, 2011. Coleção docência em formação.

BRAUDEL, F. História e Ciências Sociais: a longa duração. In: Escritos Sobre a História. São Paulo: Perspectiva, 1992, p. 41-78.

BURKE, Peter. História e Teoria Social. São Paulo: Editora Unesp, 2012.

CAIMI, Flávia Eloisa. O que precisa saber um professor de História? História e Ensino, Londrina, v.21, n.2, p. 105-124, jul./dez. 2015.

COELHO, Wilma de Nazaré Baía. A cor ausente. $2^{\circ}$ ed.- Belo Horizonte: Mazza Edições, 2009.

COELHO, M. C \& COELHO, W.B.C. As licenciaturas em história e a Lei 10.639/2003: percursos de formação para o trato com a diferença. 2018.

COELHO, M. C \& COELHO, W.B.C. Notas sobre a formação docente o saber histórico escolar nos cursos de formação de professores de história. 2019.

FERNANDES, José Oriá. Ensino de história e diversidade cultural: desafios e possibilidades. Cad. Cedes, Campinas, vol. 25, n. 67, p. 378-388, set./dez. 2005. Disponível em: http://www.cedes.unicamp.br. Acesso em: 10 jun. 2020.

FREYRE, Gilberto. Casa-grande \& senzala: formação da família brasileira sob o regime da economia patriarcal”. São Paulo: Global, 2006.

GOMES, N. L. Educação cidadã, etnia e raça: o trato pedagógico da diversidade. In: Racismo e anti-racismo na educação; repensando nossa escola. CAVALLEIRO, ELIANE (Org.). São Paulo: Selo Negro, 2001.

GOMES, N. L. Alguns Termos e Conceitos Presentes no Debate sobre Relações Raciais no Brasil: Uma Breve Discussão, 2008.

GOMES, N. L. Diversidade Étnico-Racial, inclusão e equidade na educação brasileira: Desafios, Políticas e práticas, 2010.

GOMES, N. L. Sem perder a raiz. Corpo e cabelo negro como símbolos da identidade negra. Belo Horizonte: Autêntica, 2006.

GUIMARÃES, Selva. Didática e prática de Ensino de História. Papirus Editora. $13^{\circ} \mathrm{ed}$. 2015.

HASENBALG, Carlos A. Discriminação e desigualdades sociais no Brasil. 2 ed. Graal, 2005.

MOREIRA, A. F. A recente produção científica sobre currículo e multiculturalismo no Brasil (1995-200): avanços, desafios e tensões. Revista Brasileira de Educação, nº18, p. 6581, set./out./nov./dez. 2015. 
MUNANGA, Kabengele. Rediscutindo a mestiçagem no Brasil. Identidade nacional versus identidade negra. Belo Horizonte: Autentica, 2004.

MUNANGA, Kabengele (org). Superando o racismo na escola. $2^{\circ}$ Ed. [Brasília]:

Ministério da Educação, Secretaria de Educação Continuada, Alfabetização e Diversidade, 2005.

OLIVEIRA, M. A. O negro no ensino de história: temas e representações (1979-1998). 2000. 191 f. Dissertação (Mestrado em Educação) - Faculdade de Educação, Universidade de São Paulo.

ORTIZ, Renato. Cultura brasileira e identidade nacional. São Paulo: Brasiliense, 2006.

ROCHA, Nathália Fernandes Egito; Pereira, Maria Zuleide da Costa. O que dizem sobre a BNCC? Produções sobre a Base Nacional Comum Curricular (BNCC) no período de 2010 a 2015. Espaço Currículo, v.9, n. 2, p. 215-236, mai./ago. 2016.

SKIDMORE, Thomas E. Preto no branco: raça e nacionalidade no pensamento brasileiro. Tradução: Raul de Sá Barbosa. Rio de Janeiro: Paz e Terra, 1976.

SCHWARCZ, Lílian Moritz. O espetáculo das raças: cientistas, instituições e questão racial no Brasil - 1870-1930. São Paulo: Companhia das Letras, 1993.

SANTOS, Raquel Amorim dos. [In]visibilidade negra: representação social de professores acerca das relações raciais no currículo escolar do Ensino Fundamental em Ananindeua (PA). Dissertação. (Mestrado em Educação) Universidade Federal do Pará, Instituto de Ciências da Educação, Belém, PA, 2009. 